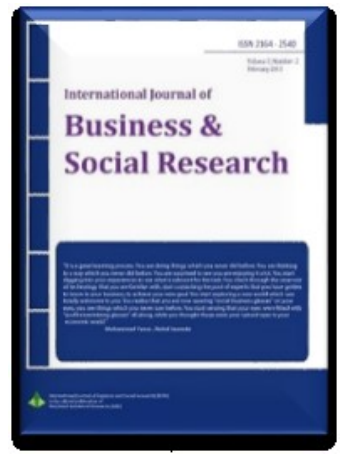

\title{
Financial Support for Civil Society Organisations in Ghana: A Study of Natural Resources and Environmental Governance
}

\author{
Samuel Kwofie', Isaac Kwasi Yankey², Godfred K. Abledu³
}

\begin{abstract}
Civil Society Support Funds (CSSFs) are becoming a common mechanism for providing financial support and capacity building to Civil Society groups in most parts of the world. Management of these funds have become a challenge to the donors with options either to channel it through intermediaries or present it themselves. Multidisciplinary and multi-sectoral approaches were adopted and supported largely with other participatory methodologies that combine social, institutional, political and economic parameters in the information collection, collation, analysis and synthesis, and for reporting. It was found out that an independent funding scheme earmarked for the Environmental Natural Resources (ENR) sector is a preferred funding mechanism for the sector. The name 'Civil Society - Natural Resource and Environmental Fund' was recommended. This scheme is perceived to be independent of any existing scheme or institution and presents a mechanism for specific targeting of ENR issues and addresses variations in CS capacities. It was concluded that the use of intermediaries for the management of donor pool funding is an effective way of finding balance between the two horns of a dilemma - the DPs or Government donor funds meant for the development of the CS capacity for accountability.
\end{abstract}

Keywords: Development, donors, environmental governance, intermediaries, natural resource.

Available Online: 20-03-2016.

This is an open access article under Creative Commons Attribution 4.0 License, 2016.

1.0

INTRODUCTION

1.01

BACKGROUND AND CONCEPTUALISATION

\footnotetext{
${ }^{1}$ Applied Mathematics Department, Faculty of Applied Science and Technology, Koforidua Polytechnic, Koforidua, Ghana, West Africa. Email: rockstahus@yahoo.com.

2 Department of Energy Systems Engineering, Faculty of Engineering, Koforidua Polytechnic, Email: ikyankey@gmail.com.

3 Applied Mathematics Department, Faculty of Applied Science and Technology, Koforidua Polytechnic. Koforidua, Ghana, West Africa. Email: godfredabledu@gmail.com.
} 
Civil Society Support Funds (CSSFs) are becoming a common mechanism for providing financial support and capacity building to Civil Society (CS) groups in most parts of the world. These funds are either Government funded, sometimes with funding support from Development Partners (DPs), or are funded directly by the Development Partners themselves. In some instances there are funds that are jointly funded by the Government and DPs. Donor-support schemes are often built on existing bi-lateral trends by various bilateral schemes aimed at brokering the relationships between the state and CS. Whilst some donors might institute and manage these funds, in some cases the transaction cost and the associated pressures make them consider alternative ways of organising and managing the support system to CS. As a result, multi-donor CS support funds have explored alternative management schemes, with the adoption of intermediary institutions or organisations. In some cases, new structures were created to manage and in others the funds were either anchored or hosted by existing organisations. Often times, these intermediaries are CS actors; there are also situations where the funds are managed by Government agencies. (Young, 2006).

\subsection{PROBLEM STATEMENT}

The option of channelling resources by the various Development Partners through intermediaries presupposes that they are also shifting risks associated with handling large scale funding to the intermediaries and as such would be looking at factors such as credibility of the organisation, management capacity, the ability to build capacity of CSOs and more importantly the enabling political environment to operate.

With the Paris Declaration on Aid Effectiveness, a number of DPs are responding to pressures to reduce transaction cost whilst increasing effectiveness and efficiency. (Kwofie, 2014). This underscores the need for the Natural Resources and Environmental Governance (NREG) programme to explore mechanisms for funding CS actors under the programme.

\subsection{RESEARCH GOAL, OBJECTIVES AND SCOPE}

The goal of the study is therefore to proposing workable, efficient and cost-effective approaches, based on assessment of existing practices in Ghana, for mobilisation, administration, management of donor funding and for transfer of funds from donors to a range of CS partners;

Specific objectives of the research include the following:

- Identify the existing funding mechanisms in the area of Natural Resources and Environment.

- To establish confidence in handling donor funds for projects.

- To provide the necessary modalities for transfer of funds to the various Civil Society Organisations (CSOs) in NREG sector.

The research is anchored around Natural Resource and Environmental Governance (NREG) sector.

\subsection{METHODOLOGY AND APPROACH}

Multidisciplinary and multi-sectoral approaches were adopted and supported largely with other participatory methodologies that combine social, institutional, political and economic parameters in the information collection, collation, analysis and synthesis, and for reporting.

In gathering the Information, qualitative data were gathered through desk studies, consultations with key informants, interviews (design and administration of structured and semi-structured questionnaires). To capture the relative perceptions of stakeholders, field visits were undertaken to hold one-on-one discussions and consultations with key respondents from the Government and CSOs (both local and international NGOs) officials. The volume of information generated required careful analysis and the use of more scientific tools, which was to provide systematic and logical trace of the research. The analysis was thus an output of a soft ware called Statistical Package for Social Sciences (SPSS) version 20. 


\subsection{LITERATURE REVIEW}

\subsection{INTRODUCTION}

The early period of development assistance to the CS sector has been through direct contact between CS groups and individual donor organisations. Although majority of the donors work within their country assistance strategies of support to Ghana, funding of the CS sector was uncoordinated. Access to funding was based on ability to source funds, with very little 'tied-funds'. It was a situation of the 'winner takes' all. There was very little information in the public domain on funding sources, and where such information exists, it is not widely publicised. Some attempts were made at what could be described as 'Private Engagement' in the disbursement of the funds, where donors engaged the services of consultants to disburse the funds. A recent development, probable fallout from the Paris Declaration on Aid Effectiveness saw a number of DPs in several parts of the globe exploring mechanisms to 'decentralise' the support to CS through intermediaries.( Kwofie, 2014).

A number of Civil Society Support Funds (CSSF) operates in Ghana at the moment. These funds support CS programmes in some of the following areas:

- Capacity Building

- Advocacy

- Public Policy

- Human Rights

- Gender

- Governance

- Civic Engagement

- Service delivery in Health, Education, Water and Sanitation

This study cites four CSSFs due to the fact that they are widely known within CS.

\subsection{CIVIL SOCIETY GOVERNANCE FUNDS (CSGF)}

The CSGF is a DANIDA support fund aimed at enhanced participation, human rights, equity, transparency and accountability to support improved delivery of services for sustainable poverty reduction within a decentralised, democratic environment. The fund, administered by the lbis Good Governance and Human Rights Programme (GG\&HRP) 4 is targeted at community based CSOs and grassroots organisations. The main thrust of the fund is the support for capacity building.

The decision making body for the fund is the CS Fund Board, with the overall responsibility for policy and supervision of funds. The board has a broad representation from within CS. There is also representation from the Government side. There is no separate set up such as a secretariat, but rather the day-to-day management of the fund is done at the Ibis programme management level.

\subsection{RIGHTS AND VOICE INITIATIVE (RAVI)}

The Rights and Voice Initiative (RAVI) is a DfID funded project with the aim of promoting rights based approaches to development with the goal of ensuring 'improved accountability and responsiveness of the Government' towards its citizens, particularly the poor. The project is targeted at strengthening the voices of people living in poverty and supports the organisations of such people and CSOs who work with them to advocate and dialogue with Government. All levels of CSOs are eligible for support but small Community Based Organisations (CBOs) will be reached and supported through larger intermediary organisations. The programme is organised at 4 levels with a Management Agency (MA) contracted by DfID as the implementation agency. The work of the MA is complemented by a Steering

\footnotetext{
4 www.ibisghana.org
} 
Committee (SC), which has an oversight responsibility and a grants sub-committee within it. The project is administered by a secretariat ${ }^{5}$.

\subsection{BUSINESS SECTOR ADVOCACY CHALLENGE FUND (BUSAC)}

BUSAC, a joint USAID, DANIDA and DfID funded private sector advocacy support programme is aimed at enabling the private sector, including business membership organisations, trades unions and media, to influence public policy formulation by undertaking appropriate research, developing evidence based policy positions and advocating those positions with Government and other private sector institutions/organisation who may be targeted by the action. Initially launched by DANIDA under the Business Sector Programme Support, it grew to attract support from the other two organisations. The fund management has been contracted by DANIDA to a consultancy firm - COWI.

The fund aims at promoting the engagement of the Private Sector in policy making and policy implementation, strengthening the capacity of representative organisations of the Private Sector to advocate for pro-business sector reform and assisting to remove bottlenecks at all levels of administration and also within the Private Sector itself. It also seeks to broaden public understanding of the role of businesses in society ${ }^{6}$.

\subsection{GHANA RESEARCH AND ADVOCACY FUND (G-RAP)}

The Ghana Research and Advocacy Programme (G-RAP) is a pooled funds scheme that provides grants to Ghanaian based institutions engaged in pro-poor public policy research and advocacy. G-RAP provides core grant support - as opposed to project support - to strengthen the capacity and funding base of these institutions. G-RAP funding targets institutions that can contribute to the national policy dialogue with Government, Parliament, District Assemblies, Donors, and Non-state Actors. Among the typical beneficiaries of G-RAP funding are think-tanks, development organizations and advocacy networks. The G-RAP is a complementary mechanism to the Ghana MDBS.

G-RAP's focus, amongst others, is to strengthen civic engagement in the Ghana's Development Agenda and promote the delivery of pro-poor policies for CS. It aims also to enhance the autonomy and capacity of NGOs to conduct evidence based research and advocacy that informs and monitors the Development Agenda, pro-poor policy processes and implementation. It is jointly financed by the DfID, DANIDA, CIDA and the Royal Netherlands Embassy, all in Ghana.

\subsection{OTHER FUNDING SCHEMES}

There are other funding schemes in existence in the country. Most of them are tied to specific programmes and themes. A number of them are aimed at supporting non-traditional CSOs. Regrettably, most of these are little known within the CS sector. Most of these funding sources can be accessed from the GAPVOD NGO directory, the UNDP Civil Society Resource Centre and RAVI websites ${ }^{7}$.

\subsection{RESULTS AND DISCUSSION}

Establishment of funding scheme in the ENR sector aimed at facilitating CS activities in the sector was well received by CS at all levels. Varied views and different opinions were expressed in relation to the structure, form and function of the funds. Whereas 62 per cent of CS expressed interest in the development of simple structures affording easy and quick access, others, constituting 38 per cent called for very rigid structure with built in control and regulatory mechanisms. A common strand running through all views expressed on funding was that the funds should be CS owned and dominated.

\footnotetext{
5 wWw.ravighana.org

6 www.busac.org

7 Information on funding schemes is also available on www.devdir.org
} 
A funding process that seeks to support the broader CS should be simple, workable and with room and scope for dialogue. It should be a scheme that provides funds on the basis of expected and anticipated results and impacts. Whereas track records and achievements in the sector might be useful for some categories of beneficiaries such as NGOs and networks, for new entrants and emerging NGOs (including non-traditional CSOs), this might not be important. Non-traditional CSOs have little engagement, if any at all with funding and might not have any track records to show. Emphasis should be placed on the quality of outputs and outcomes than the process towards achieving them. In as much as process is important for achieving results quality of results is equally important.

Based on consultations and views expressed, the following 5 mechanisms for funding were proposed.

\subsection{FUND MANAGEMENT BY EXISTING NETWORKS}

Anchoring the funding scheme into existing CS networks in the ENR sector and engage their secretariat in the administration of funds for the sector is one of the emerging proposals for administering a CSSF for the sector. The day-to-day management and reporting on the funds should be undertaken by the secretariat. There should be out sourcing of processes such as capacity building, project assessment and selection of beneficiaries, Monitoring \& Evaluation, etc. The host - organisation will be paid management fees for services rendered.

One advantage of this approach is that networks and coalitions in the sector are familiar with issues and have the advantage of determining their capacities and capabilities. The loose structure proposed also makes for ease of work, thereby facilitating results. It also eliminates costs related to the establishment of new structures. On the other hand, locating the funds in networks as proposed does not necessarily in itself guarantee efficiency and prudence in fund management. One issue that comes to the fore is the potential conflict between the network and its member organisations for funding. Networks as they are, also solicit funding from about the same sources as the member organisations. Managing a pool from which the two entities derive funding will give undue advantage to the host. In addition, out sourcing will not necessary lead to efficiency and prudence. On the contrary, the engagement of consultants will be additional burden on the fund. The process of monitoring could be expensive and a burden on resources as the number of beneficiary organisations expands. More importantly, the CS terrain is vast and always expanding. The issues in ENR sector are equally expanding as well. Outsourcing processes such as monitoring can be an expensive venture. The fact that networks have been operational does not necessarily imply that they possess the required human resource capacity to manage and administer funds of the nature that involve supporting the ENR sector. Also, the tendency for the non-traditional, non - NGO sector of CS in this type of arrangement to access funding remains unclear. Moreover, most networks in Ghana are NGO dominated, and within that they are driven by larger and more visible groups.

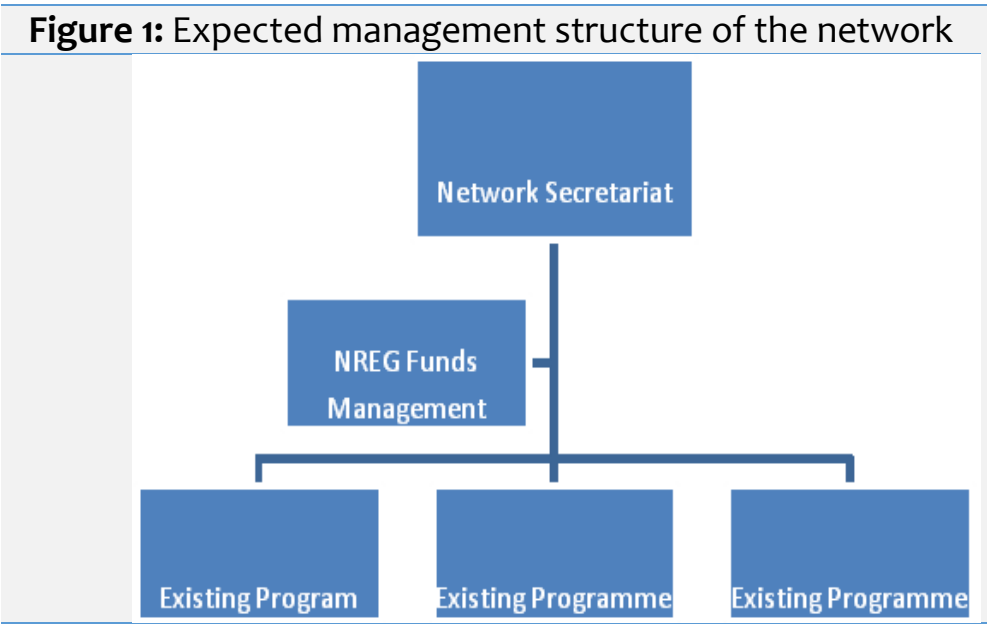

The chart (figure 1) represents the expected management structure of the network. The organisation would have its own structures already. The ENR scheme will be independent of any process ongoing, except that the secretariat provides administrative support for a fee. 


\subsection{PRIVATE SECTOR MANAGEMENT}

The privatisation of the management of funds meant for the promotion of the sector is one mechanism worth exploring. There are number of private management consultancy firms - local and international operating in Ghana with experiences in managing funds of different types and sizes. They have the appropriate human resources for funds management and also have internal control mechanisms for quality assurance and financial prudence. Private sector funds managers have over the years established high reputations in management which they stand to protect and as such will be efficient in the process.

However, the operations of the CS and the impacts they make in most cases are not immediate, but rather emerged over time. The absence of the 'profit' factor in CS work is sometimes difficult for the private sector to comprehend. In that case, measuring outputs with inputs may not necessarily be in consonance, hence conflict. In addition, most private sector actors measure results and impacts in terms of tangibles and what is visible; CS results and impacts are intangible. The cost elements of a private sector entity running a CS fund could be high due to the large and multiple nature of CS. Monitoring and in some cases mentoring which are essential to the sector will therefore become expensive ventures. (Kwofie et al., 2015).

\subsection{ANCHORING FUNDS WITHIN AN EXISTING SCHEME}

The proposal to anchor the funds with an existing CS Support Fund is one of the most preferable schemes. The assertion was that these schemes have had experiences working with CS groups of all categories and have over time developed and fine-tuned their work processes. It further asserted that these schemes have established the credibility and also draw their funds from DPs who are equally interested in ENR governance. Since the proposed ENR funds are earmarked for the sector alone, it will be prudent not to create any new structure leading to multiplicity of funds. It should just be an add-on to what is in existence and managed through their existing systems and structures. The existing organisation structure of the scheme should be maintained with only the additional responsibility of ENR funds added.

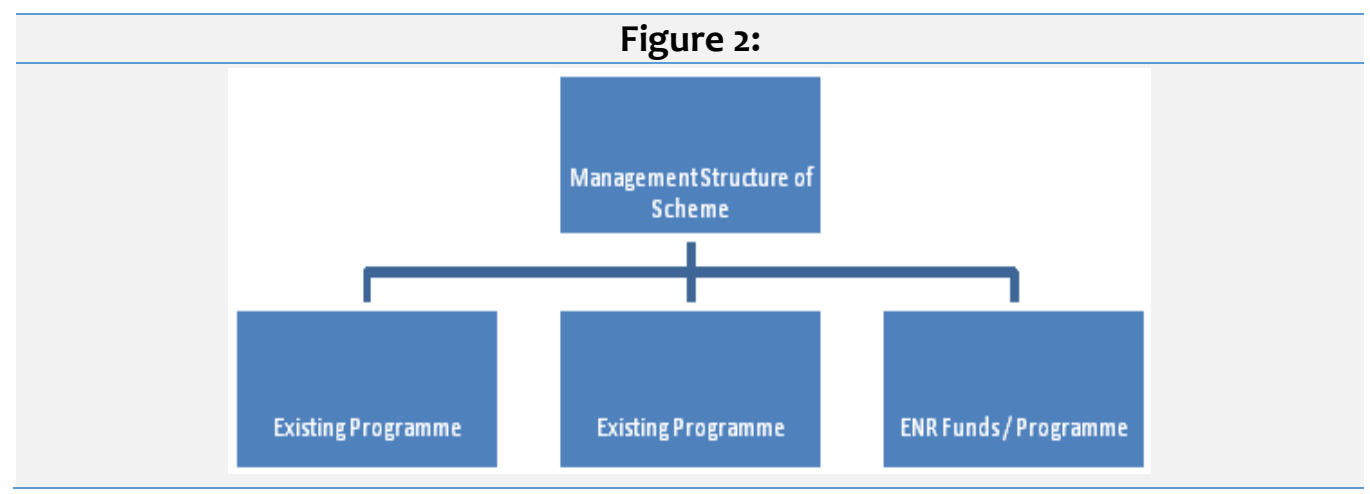

In addition, the existing schemes have had contact with CS organisations as part of its beneficiaries and have supported their capacity building over the period of engagement. Dealing with them under a new scheme will be a form of continuity of their engagement and as such there will not be any additional cost for capacity building and institutional strengthening.

This proposal comes with a number of disadvantages. First, it calls for the re-positioning and reorganisation of the work processes of the scheme. The addition of ear-marked funds to a multiple funding scheme implies the addition of more responsibilities and work, and in this case, responsibilities in a specialised staff. There is also the issue of the selection process of beneficiaries. Traditionally, NGOs, think-tank and other allied CS groups have been benefiting from most of these funds due to their capacity and ability to meet the eligibility criteria and application requirements. A large number of 
stakeholders and actors identified in the ENR sector lack the capacity to meet the eligibility criteria. Prescribing different eligibility criteria for use by such an organisation will also mean introducing new processes, which might conflict with existing work processes.

\subsection{TRIPARTITE MANAGEMENT}

A proposal similar to the structure above is that which has a tripartite governance structure comprising of CS, GoG and DPs. Under this structure, the Tripartite Committee has the overall responsibility for the funding scheme with a Fund Administrator. Other functions will be placed under the office of the Fund Administrator with centralised operations. The Tripartite Committee will perform technical support services as well as quality assurance. In addition, the committee will have the responsibility of reporting on the scheme to the Sector Group when demanded. A new office could be established for the Fund Administrator.

This scheme has the advantage of harmonising activities within the committee with the three subsectors engaged in the NREG. In addition, it reduces transaction time and cost of service delivery. The representation of the GoG on the committee also reduces the tension that exists between CS sector and Government and promotes process of dialoguing.

On the other hand, the tripartite management approach involving the three sectors limits the scope for enhanced participation in the funding process. The assumption here is that the committee will be a small one with operations within the group. Time will be of essence here since the members of the committee; especially the GoG representatives would have to, amongst other things, combine activities with that of their normal schedules. This promotes bureaucracies, which to a large extent might affect delivery of services. The single stream funding promoted under this scheme also would lead to a single eligibility criterion that might not be to the advantage of local and community level groups.

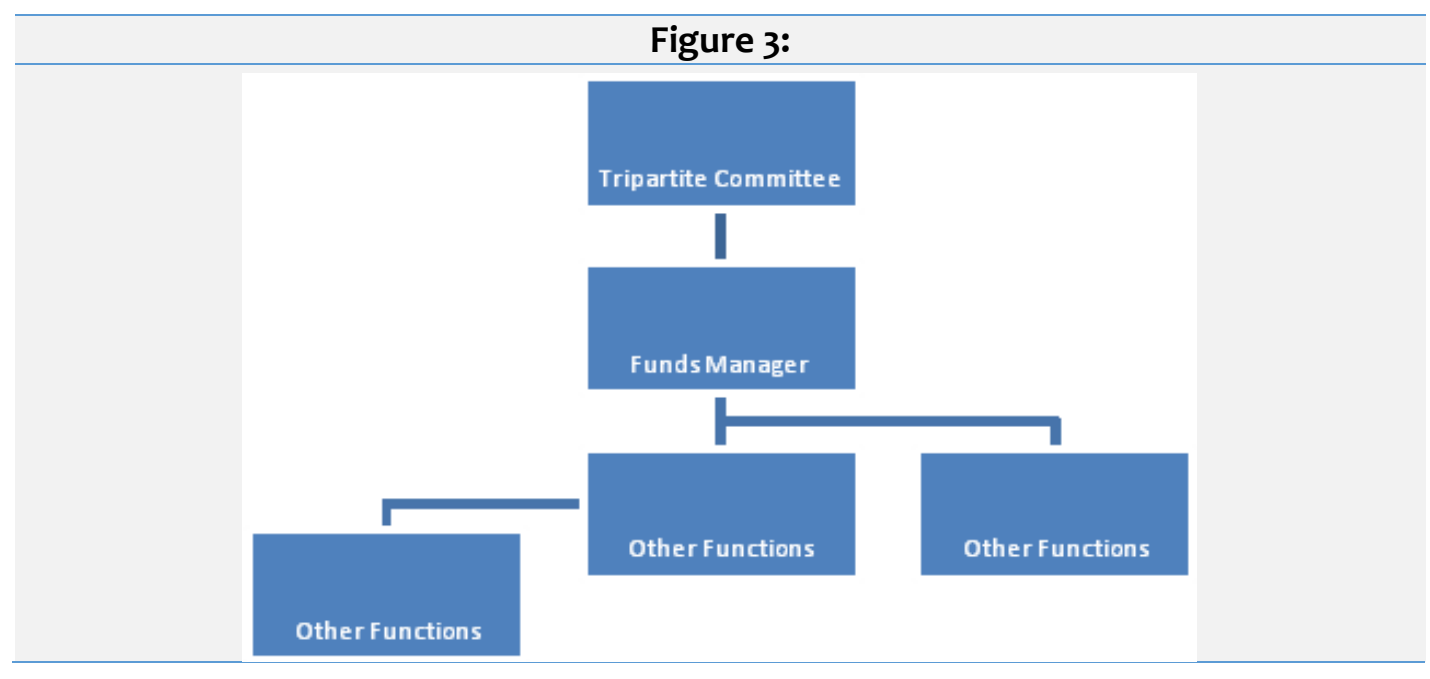

\subsection{ESTABLISHMENT OF A NEW FUNDING SCHEME}

Based on existing CSSFs and proposals from stakeholders consulted, a proposed new and independent funding scheme for support to CS engagement in the ENR sector has been established. Several views have been put forward in favour of the establishment of a new funding entity based on existing models such as RAVI and/or G-RAP. This scheme with some semblance to point three above (Anchoring Funds within an existing scheme) holds the view that earmarked funds should not be aligned to any scheme that has a broader mandate. The issues in ENR governance, though in aggregate terms translate into the general issues of good governance, poverty reduction and socio-economic development of the country, are more sector specific than thematic. As such the sub-sectors under the ENR should be targeted under a broad package. The scheme is presented under specific recommendation 


\subsection{KEY FINDINGS}

The key issues emerging from the study and the engagement process includes: First, there is limited funding for the ENR sector. Funds such as GEF/SGP are very little known by community level actors. Exhibiting CSSFs are also not earmarked for ENR, but rather for capacity building and other processes. Second, an independent funding scheme earmarked for the ENR sector support is a preferred funding mechanism for the sector. Whereas varying views were expressed about the structure and nature of the funding scheme, the general consensus was that its management should have CS representation and other ENR actors, including Government.

\subsection{RECOMMENDATIONS AND IMPLICATIONS FOR POLICY}

Based on the review of the sector and field studies, the following recommendations are worth considering: Civil Society - Natural Resource and Environmental Fund.

Having scrutinised the existing situation as well as stakeholders' contributions, an establishment of a new funding scheme to be known as Civil Society - Natural Resource and Environmental Fund was proposed. The scheme is perceived to be independent of any existing scheme or institution and presents a mechanism for specific targeting of ENR issues and addresses variations in CS capacities.

Although this structure might appear complex at a first glance, it presents a simple mode for information dissemination and sharing. In addition it has the advantage of promoting collective ownership of processes between CS and Government, with a diminishing role for Developing Partners (DPs). It addresses issues of sustainability due to the fact that it has in-built mechanisms for representation and participation of all interests. The disaggregation of funds among the various levels of CS makes for specific targeting of groups and reducing the tendency for competition that might hitherto had disqualified a number of groups due to their capacity limitations. Defining supervisory and coordinating roles for the Sector Group is one way of making information generally available in the public domain due to the broad representation of the group.

This scheme makes for a structured but less flexible funding with three funding bands. There are funding bands or lines for local and community level CSOs, NGOs and research. CSOs would then receive funding appropriate to their scale and nature of operations without recourse to meeting some sort of eligibility criteria that might not be suitable for all levels, but benefiting only a few. For instance, whereas policy or national NGO or network might be looking towards a high level of funding for its activities, a citizen's group might be demanding something very small for a specific activity.

\subsection{GOVERNANCE STRUCTURE}

The structure for this scheme comprises Steering Committee as the policy and decision making body of the scheme. A sub-committee of the steering committee will be responsible for the selection processes, quality control and quality assurance of the work of the Steering Committee. The proposed Steering Committee would be a sub-committee of the Sector Group on NREG with a broad based representation from CS, GoG and DPs. The CS component should have representation from the levels of CS identified in the EC commission's CS mapping. Chiefs should be part of CS representation. The overall policy direction for the fund will be endorsed and adopted at the Sector Dialogue Group Level.

This structure calls for the structuring of the sector group dialogue and enhancing on its policy roles with wider representation including enhance CS presence. The Steering Committee will report on the scheme on annual basis to the Sector Group and also when demanded by the Sector Group. The Steering Committee to be drawn from the Sector Group would be made up of members of the group who have experiences and expertise in the sub-sectors of ENR, CS issues, capacity building and organisation development amongst others. Membership could also be drawn from outside the Sector 
Group. A sub-committee drawn from the Steering Committee will provide technical support to the scheme and also report to the Steering Committee on activities within the scheme. The Technical Committee will provide support in the selection of beneficiary CSOs and also the assessment of outputs and results. It will also serve as the assessment and quality assurance team of the fund.

\section{Figure 4:}

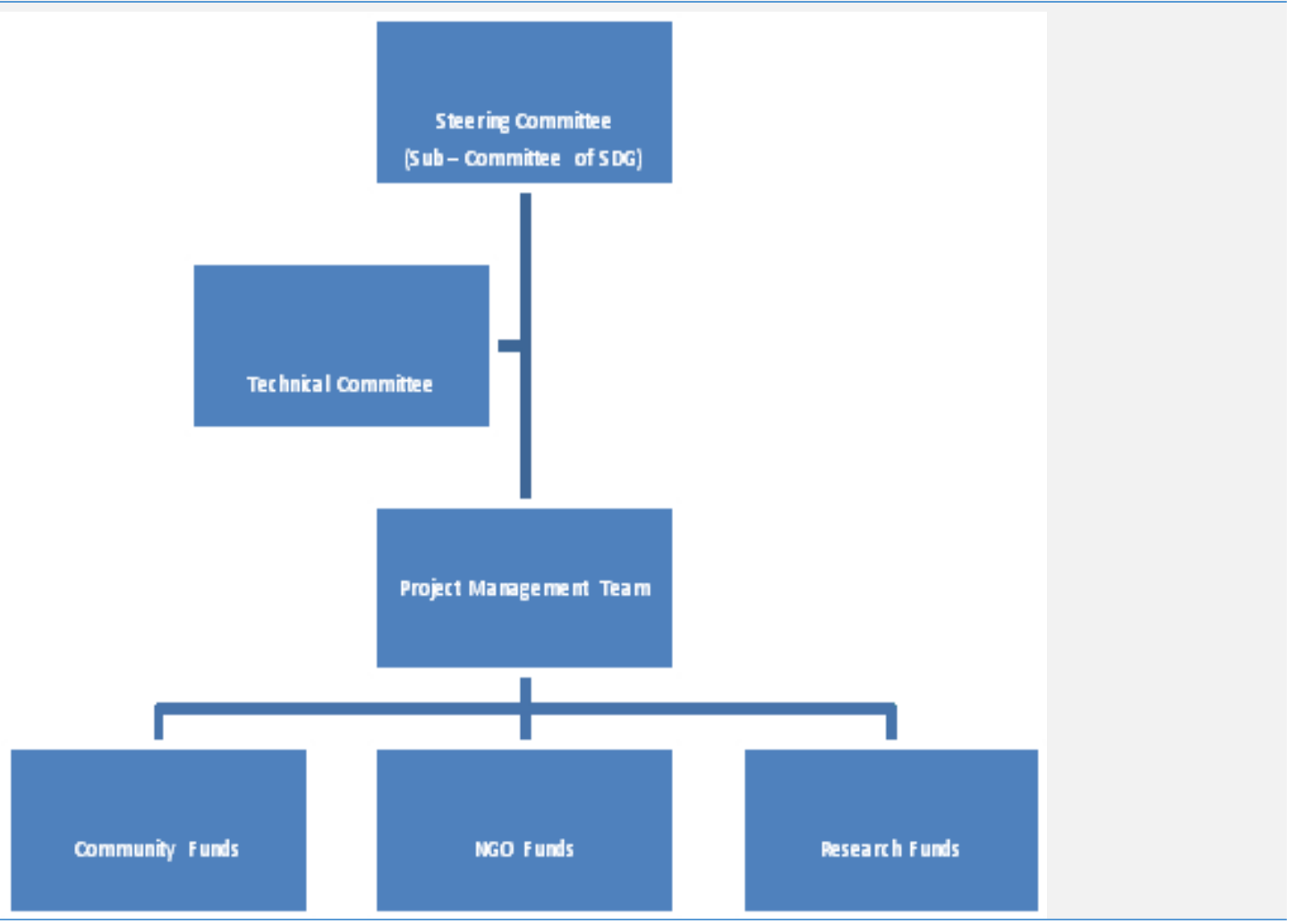

The executive activities and day-to-day management of the fund will be under a Project Management Team (PMT), under the leadership of a Fund Administrator (FA). The FA will be a member of the Technical Committee and serve as secretary to the Steering Committee. Other functions of the PMT will be, but not limited to, capacity building, gender mainstreaming, Monitoring and Evaluation (M\&E) and financial management process.

The scheme as proposed will be in three lots: The first lot targets entities such as Citizens Associations, Vocational and Work Guilds, Faith-Based Associations, Civic Unions, CBOs, etc. The second will focus on traditional NGOs and larger CBOs including networks and coalitions in ENR. The third lot will be devoted to research in the areas of policy, academia and action research. Beneficiaries for this line of funding include think-tank organisations, trade unions, individuals and groups in academia and students' thematic groups in the sector.

\subsection{CONCLUSION}

The structures proposed above provide various frameworks or schemes for funding CS activities in the ENR sector. The vision is to provide a balance between the various rationales and functions for funding for development. Funding schemes, serviced by donor pools promote the shift from the viewpoints about rationality to that of the recipients' specific viewpoints. The use of intermediaries for the management of donor pool funding is an effective way of finding balance between the two horns of a dilemma - the DPs or Government donor funds meant for the development of the CS capacity for accountability. 
There is the need for 'risk - taking' or funding for advocacy and accountability initiatives. The risk taking funding should be seen in terms of learning and innovations that support exploratory activities. Whereas NGOs as part of CS and other well established CS groups might have experiences accessing donor funding, the risk-taking funding will be a mechanism for supporting new and emerging organisations, with little or no experiences in accessing donor funding. This is worth exploring in the ENR sector. In addition, the mechanisms for delivering small grants need to be combined with investment in technical support for community capacity building at the local level.

Financial support is needed to improve on the activities of Civil Society Organisations but there is the need to monitor implementation to avoid using the support for non-budgeted programmes and activities.

\section{REFERENCES}

Civil Society Rights and Voice Initiative (Ravi) (2010). Increased support for mobilization and advocacy to improve demand for effective resource allocation, quality services and the protection of rights. www.ravighana.org

Kwofie, S. (2014). Aid Effectiveness: A Case study in Democratic Ownership and Accountability in Natural Resources and Environmental Governance in Ghana. International Journal of Business and Social Research 4(6) USA, 4(6) pp 85-96

Kwofie, S. Awuah, A., Yankey, I. K. (2015). Support to Civil Society Organisations to increase Natural Resources Management and Environmental Governance in Ghana. International Institute for Science, Technology and Education (IISTE), 6(10). (www.iiste.org)

IBIS (2014).Improving management of Ghana's natural resources. www.ibisghana.org

National Development Planning Commission (2014). Medium-Term National Development Policy Framework. (2014-2017) Assembly Press, Ghana.

Young, O.R (2006). Governance for Sustainable Development in a World of Rising Interdependencies. Background paper for the Workshop on Governance for Sustainable Development, at the Donald Bren School of Environmental Science and Management, University of California, Santa Barbara. 1214 Oct. 2006.

\section{Websites}

www.busac.org

www.devdir.org 